\title{
Formação docente e artefatos digitais: análise de Recursos Educacionais Digitais (RED) e a exploração de um repositório educacional digital
}

\author{
Rayssa A. Hitzschky ${ }^{1}$, Juliana S. Arruda ${ }^{2}$, Antônia Taticlé V. Cassiano ${ }^{1,}$ Cintia A. Lima $^{1}$, \\ Liliane Maria R. de Castro Siqueira ${ }^{1}$, José Aires de Castro Filho ${ }^{1}$ \\ 1Instituto UFC Virtual - Universidade Federal do Ceará (UFC). \\ ${ }_{2}$ Universidade Estadual do Ceará (UECE).

\begin{abstract}
\{hitzschkyrayssa, julianarruda24, taticlevieira, arrucintia,lilianeramalho1609\}@gmail.com\} aires@virtual.ufc.br
\end{abstract}

\begin{abstract}
This study sought to investigate actions of a workshop offered to teachers, through the search and analysis of Digital Educational Resources (DER) of Portuguese Language and Mathematics, from the digital educational repositor Athena. The workshop was organized in three moments: 1) Theoretical context; 2) Presentation of technical and pedagogical criteria; 3) Selection of DER through the worked repository. The results show the relevance of the formative moment for the appropriation and understanding regarding the search and analysis of resources by teachers. In addition, DER choices and explorations demonstrate particularities regarding teachers' practices, contextualized to their realities and needs.
\end{abstract}

Resumo. Este estudo buscou investigar ações de uma oficina ofertada para docentes, por meio da busca e da análise de Recursos Educacionais Digitais (RED) de Língua Portuguesa e de Matemática, a partir do repositório educacional digital Athena. A oficina foi organizada em três momentos: 1) Contextualização teórica; 2) Apresentação de critérios técnico-pedagógicos; 3) Seleção de RED por meio do repositório trabalhado. Os resultados evidenciam a relevância do momento formativo para a apropriação e compreensão no que tange à busca e à análise dos recursos pelos professores. Além disso, as escolhas e as explorações dos RED demonstram particularidades quanto às práticas dos professores, contextualizadas às suas realidades e necessidades.

\section{Introdução}

As ações e as atividades dos seres humanos apresentam-se como base dos aspectos sociais e culturais, a partir de cada momento histórico e, assim, novas ferramentas (artefatos físicos e simbólicos) surgem como forma de mediar as interações dos sujeitos com o seu meio. Segundo Vigotski (1995), a maneira como esses artefatos são utilizados influenciam os processos cognitivos de quem aprende.

A partir desse cenário, os Recursos Educacionais Digitais (RED) atuam como artefatos digitais que entrelaçam as tecnologias à descoberta de novas significações para os alunos e também para os docentes, autores dos processos de ensino e de aprendizagem. Desse modo, ressignificam-se os “(...) processos de aquisição de ferramentas, juntamente 
com o desenvolvimento específico dos métodos psicológicos internos e com a habilidade de organizar funcionalmente o próprio comportamento" [Vigotski e Luria 1996, p. 183].

Medeiros et al. (2018) consideram que os RED são recursos digitais como softwares, aplicativos educacionais e objetos de aprendizagem, estruturados a partir de instrumentos multimidiáticos como textos, imagens, animações e elementos audiovisuais. Estudos recentes como os de Hitzschky et al. (2018) demonstram o desenvolvimento profissional e a apropriação tecnológica docente, por meio de vivências práticas em oficinas com o uso de RED e a exploração de repositórios educacionais. Nesse cenário, desafios são enfrentados pelos professores, na tentativa de acessar, organizar e inserir em seus planejamentos pedagógicos os diferentes recursos do emaranhado digital.

Dessa forma, é preciso que os professores compreendam os RED e as suas funcionalidades antes deles serem inseridos nos planos de aula, a partir de vieses bem fundamentados. Assim, a seguinte questão de pesquisa surgiu: Como uma formação contribuiu com a concepção de professores sobre o uso de RED em suas práticas pedagógicas?

Este estudo, fruto de um projeto de extensão, tem como objetivo geral investigar as contribuições de uma formação de professores que abordou a análise de Recursos Educacionais Digitais (RED) de Língua Portuguesa e de Matemática, a partir do repositório educacional digital Athena. Como objetivos específicos, propõe-se: 1) Averiguar os critérios técnicos e pedagógicos selecionados pelos professores durante a escolha dos recursos; 2) Identificar os aspectos positivos e negativos dos recursos.

O Repositório Athena ${ }^{1}$ disponibiliza RED (para desktop e dispositivos móveis) de Língua Portuguesa e de Matemática dos anos iniciais e finais do Ensino Fundamental, catalogados de acordo com a matriz de referência do Sistema de Avaliação da Educação Básica. Os recursos podem ser usados de forma off-line e todo o repositório pode ser baixado em um pen-drive de até $4 \mathrm{gb}$. Ele foi desenvolvido pelo Grupo de Pesquisa e Produção de Ambientes Interativos e Objetos de Aprendizagem (PROATIVA/UFC).

A partir da problemática apontada, o estudo busca enriquecer o conhecimento que envolve a seleção e a análise de RED, envolvendo critérios pedagógicos e técnicos. Esse movimento objetiva apropriar os docentes para uma escolha fundamentada dos materiais, de forma que eles possam entender os aspectos estruturais e conceituais dos RED.

\section{Referencial teórico}

Esta seção apresentará, primeiramente, a discussão sobre os RED em contextos e práticas escolares. Em seguida, discute-se sobre os recursos digitais e a formação de professores.

\subsection{Os Recursos Educacionais Digitais (RED) e o ambiente escolar}

Os Recursos Educacionais Digitais (RED) vêm sendo utilizados na educação, por meio de suas possibilidades multimidiáticas. De acordo com Freire et al. (2019), o uso de RED aliado às experiências prévias dos estudantes, às mecânicas, os elementos de gamificação, bem como a atuação do professor como mediador, podem possibilitar uma experiência de aprendizagem com um potencial dinâmico e mais afetivo.

\footnotetext{
${ }^{1}$ https://proativa.virtual.ufc.br/athena/.
} 
Nesse contexto, Silva et al. (2016) afirmam que a utilização de RED trouxe mudanças para a dinâmica de ensino e que estamos diante de um volume demasiado de informações, tornando-se um desafio educacional saber como selecioná-las, organizálas e repassá-las aos alunos.

Uma alternativa para isso são os chamados repositórios educacionais digitais. Segundo Afonso et al. (2011), os repositórios educacionais são sistemas de informação que permitem o aproveitamento e a reutilização de RED, possibilitando a construção de um acervo dinâmico que pode subsidiar as práticas pedagógicas. Nas últimas décadas, muitas iniciativas governamentais e privadas vêm sendo desenvolvidas com o intuito de fomentar a disponibilização e o compartilhamento de RED. Exemplos de repositórios são a Plataforma Integrada MEC RED ${ }^{2}$, o Portal do Professor ${ }^{3}$, a TV Escola ${ }^{4}$ e o Núcleo de Desenvolvimento de Objetos de Aprendizagem Significativa (NOAS) ${ }^{5}$.

A Base Nacional Comum Curricular (BNCC), documento normativo que apresenta as habilidades e as competências que os educandos devem atingir em suas trajetórias escolares, apresenta um discurso de fomento ao uso das tecnologias digitais em geral. Este documento, importante balizador para a educação escolar, visa garantir a construção de uma base comum de aprendizagens [Brasil 2017], e reforça a utilização das tecnologias digitais em geral, afirmando que é preciso trabalhar e reforçar não apenas o uso fragmentado, mas uma utilização crítica e abrangente das TIC. Conforme destaca o documento, é preciso "contemplar de forma crítica essas novas práticas de linguagem e produções, não só na perspectiva de atender às muitas demandas sociais que convergem para um uso qualificado e ético das TDIC (...)" [Brasil 2017, p. 69].

Nessa conjuntura, estudos empíricos como o de Amiel et al. (2019) apontam que os docentes têm preferências na seleção de recursos educacionais digitais, compreendendo, por exemplo, a gratuidade do recurso, a disponibilidade para download e a existência de uma licença aberta. Os achados da pesquisa também revelam que os professores optam por pesquisar os recursos em buscadores on-line, como o Google, e somente depois em repositórios institucionais, como o Portal do Professor. Couto (2017) traz uma experiência de utilização de RED com alunos da Educação Básica, mostrando que as experiências pedagógicas foram enriquecidas com o emprego dos recursos.

Frente o exposto, observa-se que o uso de RED em práticas escolares tem mostrado contribuições positivas para o ensino e para a aprendizagem. Contudo, essa inserção necessita de um elemento essencial para a qualidade do seu uso: a formação docente. São os momentos formativos que buscarão apropriar os professores para um uso crítico e analítico dos RED nos planos de aula, de forma embasada.

\subsection{A importância da formação de professores para o uso de RED}

As Tecnologias de Informação e Comunicação (TIC) ocasionam uma reestruturação no ensino e na aprendizagem, possibilitando o desenvolvimento de habilidades cognitivas e de comunicação, além de flexibilizar o raciocínio [Sarmento et al. 2017].

\footnotetext{
${ }^{2}$ https://plataformaintegrada.mec.gov.br/home.

3 http://portaldoprofessor.mec.gov.br/index.html.

${ }^{4}$ https://tvescola.org.br/.

${ }^{5}$ https://www.noas.com.br/.
} 
Os estudos de Beira e Nakamoto (2016) revelam que a utilização das TIC nos ambientes educacionais pode ser considerada como um instrumento de qualificação dos processos de ensino e de aprendizagem. Neste contexto, surge um questionamento na forma como os docentes se apropriam dessas tecnologias e como esse uso pode ter um cunho pedagógico, gerando consequências educacionais benéficas. Almeida e Prado (2003), a partir desse cenário, descrevem o papel docente nos sistemas educacionais com a inserção dos artefatos tecnológicos, revelando a necessidade deste mediar processos na qual essa aplicabilidade pode possibilitar a comunicação e o diálogo em grupo.

Marcolla (2008) considera que a inclusão de artefatos digitais na educação deve ser iniciada pelo reconhecimento de toda comunidade educacional, além do contexto escolar, que vai além do ensino formal. O professor, como um dos autores desse processo, deve estar qualificado para a utilização pedagógica das tecnologias digitais, para que essas ferramentas possam ser bem aproveitadas em todo o seu potencial. Esse processo possibilitará melhorias nas metodologias e na práxis docente e, como consequência, pode trazer resultados satisfatórios para os processos de aprendizagem.

Os estudos de Couto (2017), Freire et al. (2019) e Hitzschky et al. (2018) revelam que a formação docente deve trazer temas e elementos das TIC como alternativa para as situações de aprendizagem, por meio de metodologias que incluam esses artefatos em seus planejamentos. Sendo assim, torna-se imprescindível refletir acerca de como os professores podem enxergar e compreender na prática e, em sua atuação, as possibilidades que os RED podem proporcionar para as situações de sala de aula.

Na próxima seção, serão descritos os procedimentos metodológicos do estudo.

\section{Procedimentos metodológicos}

O presente estudo foi realizado no âmbito do projeto de extensão "Projeto Athena Desenvolvimento e uso de um repositório virtual aberto: importância da catalogação de Recursos Educacionais Digitais (RED), do Grupo de Pesquisa e Produção de Ambientes Interativos e Objetos de Aprendizagem (PROATIVA/UFC). A pesquisa é qualitativa, pois os investigadores estiveram em contato direto com os fenômenos. O estudo é descritivo, pois interessou-se pelos significados do processo [Bogdan e Biklen 1991].

A oficina foi ministrada em novembro de 2019 para 11 (onze) professores da Educação Básica de escolas públicas, com carga horária de 4 horas. O principal propósito da oficina foi apropriar os professores para a seleção e análise de RED, a partir do repositório educacional digital Athena, por meio de critérios pedagógicos e técnicos.

A oficina foi composta por três momentos distintos. A primeira caracterizou-se por uma contextualização teórica sobre RED, tipos de RED e exemplos de repositórios educacionais digitais, bem como licenças de uso, como a Creative Commons. A segunda fase foi composta pela apresentação e exemplificação de critérios pedagógicos e técnicos, a partir de testes pedagógicos, abrangendo aspectos como Representação, Sequenciamento, Navegabilidade, Feedback, Nivel de escolaridade, Contextualização e Conteúdo [Matos et al. 2010]. Em linhas gerais, a Representação (icônica ou simbólica) consiste da apresentação do conceito por meio de uma imagem. O Sequenciamento diz respeito à abordagem do conteúdo a partir de um conceito mais básico, partindo para um mais avançado. A Navegabilidade (linear ou não linear) compreende a distribuição das atividades em níveis. O Feedback refere-se ao retorno dado ao usuário, podendo ser 
positivo ou negativo. O Nivel de Escolaridade avalia se o conteúdo e os elementos de design (botões, layout, imagens) estão de acordo com o ano sugerido. A Contextualização abrange os aspectos que relacionam o conteúdo à realidade do aluno e o Conteúdo contempla a abordagem dos conceitos de modo correto e completo.

$\mathrm{Na}$ terceira fase, os formadores propuseram que os docentes se dividissem em grupos, para a exploração do Repositório Athena, em um momento de "Reflexão sobre a ação". De forma colaborativa, os docentes selecionaram um RED de Língua Portuguesa ou de Matemática do repositório, a partir dos testes pedagógicos apresentados na contextualização teórica. Ao final, os participantes apresentaram as análises, demonstrando uma proposta participativa para ser utilizada com os alunos.

Os instrumentos utilizados para a coleta dos dados foram a observação participante, diário de campo, registros fotográficos, bem como conversas informais. Ao final do momento formativo, um formulário de avaliação do Google Drive para avaliação foi enviado para os docentes, visando entender as contribuições da formação. Desse modo, as ações da pesquisa (Figura 01) foram divididas da seguinte maneira: 1) Contextualização teórica inicial; 2) Apresentação dos testes pedagógicos, considerandoos para a seleção e para a análise dos RED; 3) Reflexão sobre a ação, envolvendo a exploração, a seleção e a análise colaborativa dos recursos educacionais.

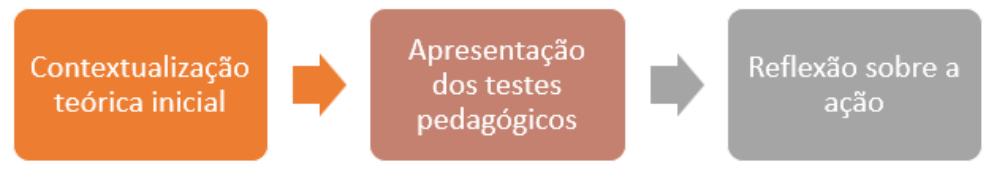

Figura 01. Ações da pesquisa

Os dados foram analisados a partir da observação participante, atentando-se para as interações, análises e depoimentos dos professores. Os registros em diário de campo foram analisados, buscando confrontá-los com os objetivos da investigação. Por fim, foi realizada a análise do questionário on-line do Google Drive, de modo que possíveis contribuições e pontos de aprimoramento da oficina fossem percebidos.

Os procedimentos metodológicos considerados para a investigação foram pensados conforme o entendimento de que é fundamental que a inserção de RED em sala de aula requer, antes de mais nada, que os docentes compreendam os recursos em seus aspectos pedagógicos e técnicos. Uma escolha e análise bem consolidadas constituise um movimento crucial para uma utilização crítica dos recursos selecionados.

$\mathrm{Na}$ seção a seguir, os resultados do estudo serão apresentados.

\section{Resultados e Discussões}

Esta seção está organizada, primeiramente, a partir das análises colaborativas dos RED feitas pelos professores. Em seguida, a avaliação da oficina será apresentada, a fim de demonstrar as contribuições deste momento formativo para os docentes.

\subsection{Análises colaborativas dos Recursos Educacionais Digitais (RED)}

Como momento prático da formação, solicitou-se aos professores que eles explorassem colaborativamente o Repositório Athena e selecionassem um recurso (para desktop) de 
Língua Portuguesa ou de Matemática para análise, a partir dos testes pedagógicos trabalhados na apresentação teórica. Os docentes organizaram-se em quatro grupos.

Após a exploração do repositório, as equipes selecionaram os seguintes RED: Provérbios - Sujeito indeterminado nos provérbios, voltado para o ensino de Língua Portuguesa no $8^{\circ}$ ano; Batalha Naval Rived, voltado para o ensino de Matemática no $9^{\circ}$ ano; e Português Popular Que música é essa?, para o ensino de Língua Portuguesa no $6^{\circ}$ ano. Vale ressaltar que este último RED foi analisado por duas equipes.

O RED Provérbios - Sujeito indeterminado nos provérbios (Figura 02) trabalha, a partir de exercícios práticos, o conceito de sujeito indeterminado a partir de provérbios, bem como os efeitos de sentido desse termo sintático nas frases propostas.

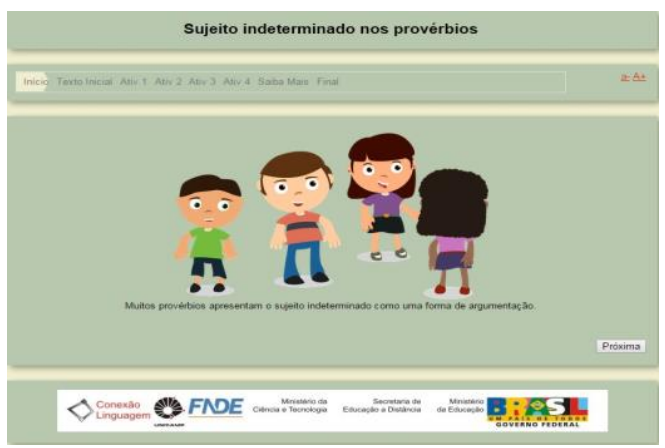

Figura 02. Imagem do RED Provérbios - Sujeito indeterminado nos provérbios

Quanto à análise do recurso, o primeiro grupo demonstrou ter compreendido os critérios de análise dos testes pedagógicos. Segundo os docentes, o recurso apresenta uma Representação simbólica, porque traz uma imagem que auxilia o usuário no entendimento do conceito de sujeito indeterminado. O recurso traz um Sequenciamento do conteúdo, pois segue uma abordagem que vai de um conceito mais básico para um mais avançado. Apresenta, ainda, uma Navegabilidade linear, pois, para os professores, o usuário deve seguir a sequência proposta pelo RED. Trabalha Feedbacks, por meio de comentários positivos ou corretivos, conforme o usuário acerte ou erre as questões.

No que se refere ao Nivel de Escolaridade, os docentes classificaram que o recurso está adequado ao nível proposto, no entanto, a equipe ressaltou que ele deve ser visto com ressalvas pelo professor antes de inseri-lo em sua prática pedagógica, pois "precisa de aula teórica sobre gramática e, mais especificamente, sobre provérbios" (Professor 1), demonstrando que os docentes tiveram um olhar crítico e reflexivo em relação ao recurso, analisando-o conforme os seus planejamentos e as integralizações curriculares. Para a Contextualização, os docentes afirmaram que o conteúdo foi trabalhado de modo contextualizado com elementos da realidade dos alunos.

Em relação ao Conteúdo, para os professores, o recurso contempla uma abordagem correta da temática. Os docentes destacaram também a ludicidade, a usabilidade simples e fácil, bem como os feedbacks dados para o aluno como aspectos positivos do recurso. Contudo, a linguagem técnica, a forma mecanicista de abordagem do conteúdo, bem como a ausência de elementos interativos, tais como animações e vídeos, foram apontados como aspectos negativos, evidenciando que os docentes demonstraram ter uma visão interativa e participativa de uso dos RED.

O segundo grupo analisou o RED Batalha Naval Rived (Figura 03), que apresenta situações de cálculo da distância entre dois pontos, de acordo com as 
coordenadas da trajetória. De acordo com a análise, os professores mostraram compreensão acerca dos testes pedagógicos. Dessa maneira, eles verificaram que o recurso apresenta Representação icônica, uma vez que há uma imagem que permite a percepção do assunto trabalhado. O Sequenciamento foi considerado incompreensível, pois a abordagem do conceito é tratada de forma confusa no recurso, exigindo, assim, uma maior explanação da temática pelo professor. Para os docentes, a Navegabilidade segue uma linearidade entre o seu conteúdo. Os Feedbacks foram considerados negativos, pois não há um retorno construtivo e contextualizado para o usuário.

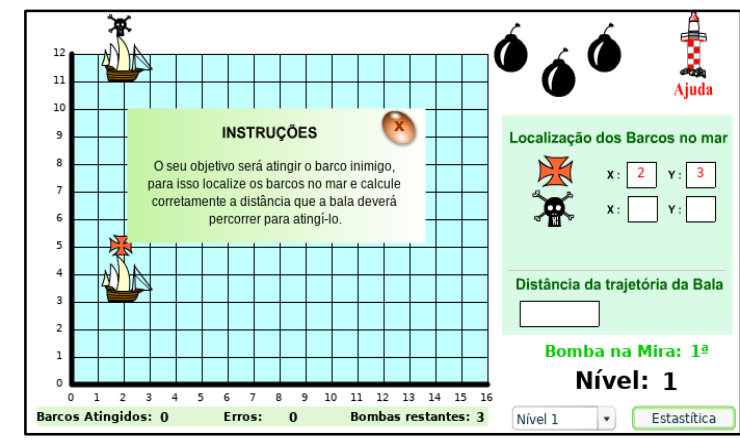

Figura 03. Imagem do RED Batalha Naval RIVED

Sobre o Nivel de Escolaridade, o recurso foi considerado inadequado para o $9^{\circ}$ ano, sendo mais apropriado, na visão dos docentes, para o $3^{\circ}$ ano do Ensino Médio. Para eles, o recurso não apresenta uma Contextualização do conteúdo, dificultando, assim, a utilização do RED pelos alunos. Segundo o grupo, o Conteúdo também é trabalhado de modo incompleto e incorreto. Como aspectos positivos, os docentes identificaram o layout simples e a familiaridade da temática "batalha naval". Já os aspectos negativos levantados pelos professores foram o fato de não haver espaço apropriado para a realização dos cálculos matemáticos necessários para a exploração do conceito, bem como a falta de explicação e opção de ajuda para a utilização do recurso.

O RED Português Popular Que música é essa? (Figura 04) aborda as variedades linguísticas, por meio de palavras e expressões empregadas na linguagem coloquial. No que se refere à análise, o terceiro grupo salientou que o recurso apresenta Representação simbólica, pois apresenta um tabuleiro de uma palavra-cruzada e a bandeira do Brasil. Para os docentes, não há um Sequenciamento das atividades. A Navegabilidade é não linear, o que possibilita ao usuário avançar para a atividade que desejar. Os professores classificaram os Feedbacks como positivos, pois o usuário recebe um retorno dos acertos e dos erros durante o RED. Para eles, o Nivel de Escolaridade está adequado para o ano.

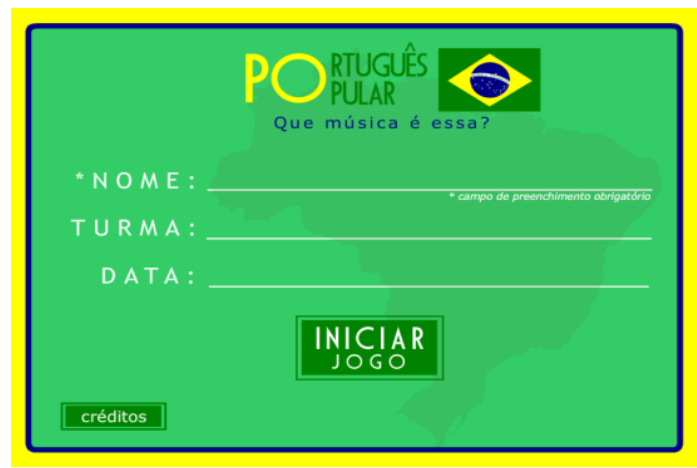

Figura 04. Imagem do RED Português Popular Que música é essa? 
Para os professores, a Contextualização foi entendida como limitada, porque não há alusão a elementos do cotidiano dos alunos. Em relação ao Conteúdo, os docentes citaram as variações linguísticas, porém não mencionaram se o tema foi explorado de maneira correta e completa. Os aspectos positivos elucidados pela equipe foram a linguagem compreensível, a usabilidade fácil e o relatório com os acertos e os erros do aluno ao final do RED. Quanto aos aspectos negativos, os docentes relataram a incoerência do título do recurso com o conteúdo abordado, pois não há menção às músicas populares nas atividades propostas. Sobre esse aspecto, a equipe defendeu a necessidade de haver uma explicação nos "Créditos" do recurso, evidenciando, mais uma vez, o olhar crítico do professor acerca do desenvolvimento pedagógico do recurso.

Na análise sobre o RED Português Popular Que música é essa? feita pelo quarto grupo, os integrantes afirmaram que o recurso não evidencia nenhum tipo de Representação, diferentemente da análise feita anteriormente, mostrando os olhares diversos sobre um mesmo recurso. Para os professores, o Sequenciamento ocorre em uma única etapa, pois não se verifica uma progressão na abordagem da temática. A Navegabilidade não foi considerada linear. Os Feedbacks foram entendidos, pelos docentes, como satisfatórios. De acordo com os integrantes do grupo, o Nivel de Escolaridade está adequado para o ano proposto.

No que tange à Contextualização, a equipe não identificou elementos que estejam próximos da realidade dos alunos. Em relação ao Conteúdo, os docentes informaram que o recurso aborda o assunto "Ortografia", contudo, não especificaram se o tema é trabalhado de maneira correta. Como aspectos positivos, consideraram a variedade de temas linguísticos contemplados no recurso, tais como "Concordância Verbal", “Acentuação de palavras" e "Variações Linguísticas". Além disso, outro aspecto importante apontado foi a facilidade de uso do recurso. No entanto, a ausência de fases, a impossibilidade do aluno refazer a atividade sem ter que reiniciar o RED e a ausência de orientação quanto ao uso do recurso foram aspectos apontados como negativos. Cabe salientar que, apesar de algumas lacunas evidenciadas no desenvolvimento, o recurso foi aprovado, não só pelos participantes da terceira e quarta equipe, mas também por integrantes de outros grupos. Segundo um professor participante da oficina, o RED Português Popular Que música é essa? pode ser utilizado, inclusive, em práticas pedagógicas nas turmas de Educação de Jovens e Adultos (EJA).

Diante das análises feitas, observou-se que os docentes mostraram apropriação dos conceitos teóricos trabalhados, demonstrando a relevância da formação docente para a construção de um olhar amplo acerca de aspectos pedagógicos e técnicos que permeiam um RED. As análises colaborativas, repletas de singularidades, revelam a importância de situações nas quais os professores precisam ser os protagonistas no momento de seleção e análise aprofundada dos recursos utilizados por eles. A percepção de tais aspectos é fundamental para a utilização dos RED em práticas pedagógicas.

\subsection{Avaliação da oficina: olhares dos professores sobre o momento formativo}

Ao final da oficina foi aplicado um formulário de avaliação final. Dos 11 (onze) participantes, 10 (dez) responderam, corroborando com o engajamento e a participação efetiva dos docentes nos momentos teóricos e práticos.

Quando questionados sobre a possibilidade de utilização e aplicação em sala de aula dos conhecimentos apresentados e discutidos ao longo da formação, 100\% dos 
professores afirmaram que poderão fazer uso dos conhecimentos obtidos para subsidiar a inserção de Recursos Educacionais Digitais em suas ações didático-pedagógicas.

No que se refere aos pontos de sucesso da oficina, os professores ressaltaram o alinhamento entre teoria e prática para uma maior apropriação dos conceitos que perpassam o processo de análise de RED, como se pode verificar no seguinte depoimento: "Explicação teórica inicial para posterior prática" (Professor 2).

Além disso, "a avaliação dos recursos" (Professor 3), as "dicas de exercícios práticos" (Professor 4), como também "a interação, praticidade e troca de experiências" (Professor 5) foram aspectos positivos destacados como uma contribuição da oficina para as práticas docentes. Tais informações reforçam que os professores perceberam a importância da formação ofertada para a apropriação de saberes referentes à análise de RED para a utilização em sala de aula.

\section{Considerações finais}

A partir do desenvolvimento da oficina, pode-se perceber que a experienciação de situações práticas em sala de aula pode trazer benefícios para a formação dos professores, tendo em vista que a partir dessa vivência, os docentes conseguem refletir sobre diferentes maneiras de utilizar os artefatos digitais em sua práxis no contexto educacional. A avaliação positiva dos professores sobre a oficina constata esta importância, evidenciando como as formações docentes são essenciais para a apropriação, o planejamento e a organização de saberes referentes à análise de RED para a posterior utilização em sala de aula.

Conclui-se que a relação entre os recursos digitais e os processos de ensino e de aprendizagem devem ser caracterizados pela mediação entre docentes, aprendentes e os recursos tecnológicos de forma estruturada e pedagogicamente organizada. Como propostas de trabalhos futuros, pretende-se abranger outras áreas de conhecimento. Sendo assim, este estudo espera trazer contribuições para o contexto pedagógico aliado ao uso das tecnologias digitais, tema de interesse no momento atual.

\section{Referências}

Afonso, M. C. L.; Eirão, T. G.; Melo, J. H. M. et al. (2011). "Banco Internacional de Objetos Educacionais (BIOE): tratamento da informação em um repositório educacional digital". Perspectivas em Ciência da Informação. v. 16, n. 3, p. 148-158.

Almeida, M. E. B.; Prado, M. E. B. B. (2003). "Criando situações de aprendizagem colaborativa". In: IX Workshop de Informática na Escola, pp. 53-60.

Amiel, T.; Mesquita, R.; Oddone, A.; Alexandre, M. E.; Miguel, G.; Figueirôa, M. F. S. (2019). "Recursos educacionais e abertura: Percepções e práticas docentes no ensino superior”. VIII Congresso Brasileiro de Informática na Educação. XXV Workshop de Informática na Escola. Brasília: DF.

Beira, D. de G.; Nakamoto, P. T. (2016). "A Formação docente inicial e continuada prepara os Professores para o Uso das Tecnologias de Informação e Comunicação (TICs) em sala de aula?". V Congresso Brasileiro de Informática na Educação (CBIE). Anais do XXII Workshop de Informática na Escola (WIE). Uberlândia: MG. 
Brasil. Ministério da Educação. (2017). "Base Nacional Comum Curricular.” Brasília: MEC/Secretaria de Educação Fundamental.

Bogdan, R.; Biklen, S. (1991). "Investigação qualitativa em educação: uma introdução à teoria e aos métodos". Portugal: Porto. 336p.

Couto, Z. K. (2017). “O uso de recursos educacionais digitais na educação básica (REDEB): relato de experiência". Revista Práxis: saberes da extensão, João Pessoa, v. 5, n. 9, p. 34-39, maio/ago.

Freire, R. S.; Figueiredo, M. V. C.; Hitzschky. R. A; Sousa. D. C.; Júnior, F. G. G.; Castro-Filho, J. A. (2019). "Recurso Educacional Digital (RED) para Trabalhar o Gênero Cardápio: Qual é o seu pedido?". Anais do IV Congresso sobre Tecnologias na Educação (Ctrl+E). Recife: PE.

Hitzschky, R. A.; Arruda, J. S.; Siqueira, L. M. R. C.; Castro-Filho, J. A. (2018). “A utilização de Recursos Educacionais Digitais (RED) de Língua Portuguesa no Ensino Fundamental e a formação docente: a inserção de RED em sala de aula." Revista Tecnologias na Educação, Ano 11, n/vol.31, Edição Temática XII - IV Congresso sobre Tecnologias na Educação.

Marcolla, V. (2008). "Como professores e alunos percebem as tecnologias de informação e comunicação nos cursos de licenciatura". In: Anais da Associação Nacional de Pós-Graduação e Pesquisa em Educação. Minas Gerais p. 1-13.

Medeiros, N. A. A. de; Xavier, C. R. S.; Melo, E. M. de; Andrade, M. A. A. de; Maia, D. L. (2018). "Recursos educativos digitais: uma revisão de literatura em anais de congressos em Informática na Educação". In: III Congresso sobre Tecnologias na Educação.

Matos, C. J. R.; Souza, M. F. C.; Fernandes, A. C.; Lima, L. L. V.; Castro-Filho, J. A.; Pequeno, M. C. (2010). "Avaliando Objetos de Aprendizagem a partir de Testes Pedagógicos”. In: XXI Simpósio Brasileiro de Informática na Educação, João Pessoa. Anais do SBIE. Porto Alegre: Sociedade Brasileira de Computação. v. 1. p. 1-10.

Sarmento, N, V.; Santos, D.; Barros, F, A.; Batista, C.; Pinheiro, R.; Fumes, N. (2017). "Pessoas aparecem sinalizando e fica algo bem próximo a realidade: o software Lepe como possibilidade para uso do trabalho docente na educação de surdos". VIII Congresso Brasileiro de Informática na Educação. XXV Workshop de Informática na Escola. Recife: PE.

Silva, C.; Osmundo, M. L. F.; Hitzschky, R. A; Brito, M. A. F.; Castro-Filho, J. A.; Medeiros, M. D. (2016). "Processo de criação de um repositório educacional digital: procedimentos de busca, seleção e categorização de Recursos Educacionais Digitais (RED)". Anais do Congresso Regional sobre Tecnologias na Educação. Natal: RN.

Vigotski, L. S. (1995). “Obras escogidas”. Madrid: Visor Distribuidores. v. 3.

Vigotski, L. S; Luria, A. R. (1996). "Estudos sobre a história do comportamento: o macaco, o primitivo e a criança". Porto Alegre: Artes Médicas. 